Linha D'Água (Online), São Paulo, v. 30, n. 1, p. 9-33, jun. 2017

\title{
DEBATE ELEITORAL PORTUGUÊS: PRESIDENCIALIZAÇÃO E ESTRATÉGIAS DE ATENUAÇÃO LINGUÍSTICA EM SITUAÇÃO DE CONFRONTO POLÍTICO
}

\author{
PORTUGUESE ELECTORAL DEBATE: PRESIDENTIALIZATION
}

AND LINGUISTIC MITIGATION STRATEGIES IN SITUATIONS OF POLITICAL CONFRONTATION

\author{
Maria Aldina Marques* \\ Universidade do Minho, Braga, Minho, Portugal
}

\begin{abstract}
Resumo: Num contexto de progressiva presidencialização das campanhas eleitorais para eleições legislativas, pretende-se estudar a atenuaç̃ão como uma característica do debate políitico eleitoral português, um gênero do discurso político marcado pela interseç̃ó com o discurso mediático televisivo. 0 debate políico eleitoral é um gênero agónico, de confronto direto entre participantes-adversários, que pretendem obter a adesão dos eleitores pelas propostas que apresentam e também, señ̃o sobretudo, pela descredibilização do adversário político. Este confronto não é, contudo, absoluto, pois os interlocutores têm que garantir dimensões básicas da comunicação políitca, assegurando, pela construção, negociaç̦̃o e cogestão da relação interpessoal, a preservaç̣̃o de uma imagem individual positiva na relação com o eleitorado. Estabelecemos como hipótese que, neste processo, a atenuação linguística constitui uma estratégia nuclear, realizada em cada momento do debate segundo procedimentos linguístico-discursivos diversos. 0 debate eleitoral analisado realizou-se em maio de 2011, na RTP, entre Pedro Passos Coelho, líder do Partido Social Democrata, e futuro primeiro-ministro, e José Sócrates, do Partido Socialista, primeiro-ministro em funcọoes, na altura.
\end{abstract}

Palavras-chave: Debate político; Discurso da mídia; Mitigação linguística; Estratégias discursivas;; Contexto.

\begin{abstract}
In a context of increasing presidentialization of legislative election campaigns, I aim to study mitigation as a feature of the Portuguese electoral political debate, a genre of political discourse marked by the intersection with the television media discourse. It is a discursive genre of confrontation between participants-adversaries, seeking for the adhesion of voters by the proposals that they present and also, if not mainly, by the discredit of the political opponent. However, confrontation is not absolute, as the interlocutors must guarantee basic dimensions of political communication, ensuring by the construction, negotiation and co-management of the interpersonal relationship the preservation of a positive individual image in relation to the electorate. I hypothesize that, in this process, linguistic mitigation constitutes a nuclear strategy, carried out in each moment of the debate according to different linguistic-discursive mechanisms. The electoral debate here analysed was held in May 2011 in RTP between Pedro Passos Coelho, leader of the Social Democratic Party, and future prime minister, and José Sócrates, of the Socialist Party, prime minister in office, at the time.
\end{abstract}

Keywords: Political Debate; Media Discourse.; Linguistic Mitigation; Discursive Strategies; Context.

* Professora doutora da Universidade do Minho - UM, Braga, Minho, Portugal; membro do CEHUM; mamarques@ilch.uminho.pt 
Linha D'Água (Online), São Paulo, v. 30, n. 1, p. 9-33, jun. 2017

\section{Introdução}

Num contexto de progressiva presidencialização ${ }^{1}$ das campanhas eleitorais, pretende-se estudar as características do debate político eleitoral como género do discurso político marcado pela interseção com o discurso mediático televisivo. O debate político eleitoral configura uma das interações verbais prototípicas das campanhas eleitorais em Portugal, não só nas eleições presidenciais, mas também, e em particular, nas eleições legislativas. $\mathrm{O}$ objetivo principal visa relacionar as características do debate político eleitoral na televisão com a atenuação linguística enquanto estratégia discursiva ao serviço da atividade argumentativa-discursiva.

Desenvolvemos o nosso trabalho num quadro teórico enunciativo-pragmático, de análise dos discursos em interação (Kerbrat-Orecchioni, 2005), em que o pressuposto da contextualidade do sentido determina o tratamento do objeto de análise, quer a um nível global, a que se agrega nomeadamente o conceito de género, quer ao nível local, cotextual. A metodologia usada é descendente-ascendente, na medida em que partimos do contexto global, do tipo de situação política e social, do género discursivo, para o contexto local, e em particular para a análise de unidades linguísticas de nível micro, a fim de retornar ao nível global e às características do género.

Selecionámos para análise o último debate da campanha para as eleições legislativas de 2011, com a duração de 1 hora, entre os "candidatos" a Primeiro-Ministro, José Sócrates (JS), líder do Partido Socialista e Primeiro-ministro de março de 2005 a junho de 2011, e Pedro Passos Coelho (PPC), líder do Partido SocialDemocrata, Primeiro-ministro indigitado em 15 de junho de $2011^{2}$.

As eleições legislativas ocorreram no dia 5 de junho e o período de campanha eleitoral decorreu entre 22 de maio e 3 de junho desse mesmo ano. Foram eleições antecipadas, após a demissão do Primeiro-Ministro, José Sócrates, devido ao chumbo do PEC 4 (Programa de Estabilidade e Crescimento) pela oposição, sendo o PSD de PPC o maior partido da oposição.

1 Sobre o conceito de presidencialização, ver Poguntke \& Webb (2005). O viés executivo, com crescimento de uma elite política, internacionalizada, e, por outro lado, um eleitorado flutuante são indicadores fortes deste processo de presidencialização.

2 Cada legislatura tem a duração de 4 anos. 
Linha D'Água (Online), São Paulo, v. 30, n. 1, p. 9-33, jun. 2017

O debate, moderado pelo jornalista Vítor Gonçalves, foi transcrito de acordo com as convenções de transcrição propostas pelo grupo Val.Es.Co (BRIZ, 2013).

\section{Contextualizar os debates eleitorais portugueses}

A consideração, para análise, do lugar e características do debate nas eleições legislativas em Portugal impõe a abordagem de algumas questões mais amplas relativas à situação política e social.

Portugal tem um regime semipresidencial ${ }^{3}$. Esta categorização não é consensual constituindo-se como tópico de discussão no âmbito da Ciência Política. De facto, nem todos os analistas políticos partilham essa designação, preferindo-lhe, alguns, a designação de regime parlamentarista (MARQUES, 2016, FREIRE \& PINTO, 2005, ESPÍRITO SANTO, 2007).

A orientação ideológica e a composição do Governo resulta de um outro ato eleitoral geral, as eleições legislativas, em que são os partidos que vão a sufrágio. É o Presidente da República (PR) que convida o partido vencedor a formar governo; o Primeiro-Ministro é nomeado pelo PR, como determina a constituição portuguesa ${ }^{4}$.

Apesar de serem os partidos que vão a votos, as campanhas têm vindo a personalizar-se, centrando-se na figura do líder partidário. A semelhança face às campanhas eleitorais para a Presidência da República permite que se fale de presidencialização das campanhas legislativas. Os cartazes das eleições legislativas em que se enquadra o debate em análise (cartazes 1 e 2, de Pedro Passos Coelho e José Sócrates, respetivamente) dão conta desta vertente da personalização e presidencialização das campanhas. O confronto com os cartazes das eleições presidenciais (cartazes 3 e 4) faz sobressair as semelhanças. Ainda que esta identificação não seja obviamente total, nomeadamente porque os logotipos dos partidos, no primeiro caso, dão lugar ao nome dos candidatos, enquadrados pelas cores da bandeira portuguesa, no segundo caso, a verdade é que os quatro cartazes são similares no que

3 O Presidente da República é eleito por sufrágio direto.

4 "O primeiro-ministro é nomeado pelo Presidente da República, ouvidos os partidos representados na Assembleia da República e tendo em conta os resultados eleitorais." (Artigo 187. , da Constituição da República Portuguesa). 
Linha D'Água (Online), São Paulo, v. 30, n. 1, p. 9-33, jun. 2017

concerne à saliência da imagem. Há um rosto que assume a responsabilidade do slogan e da candidatura.
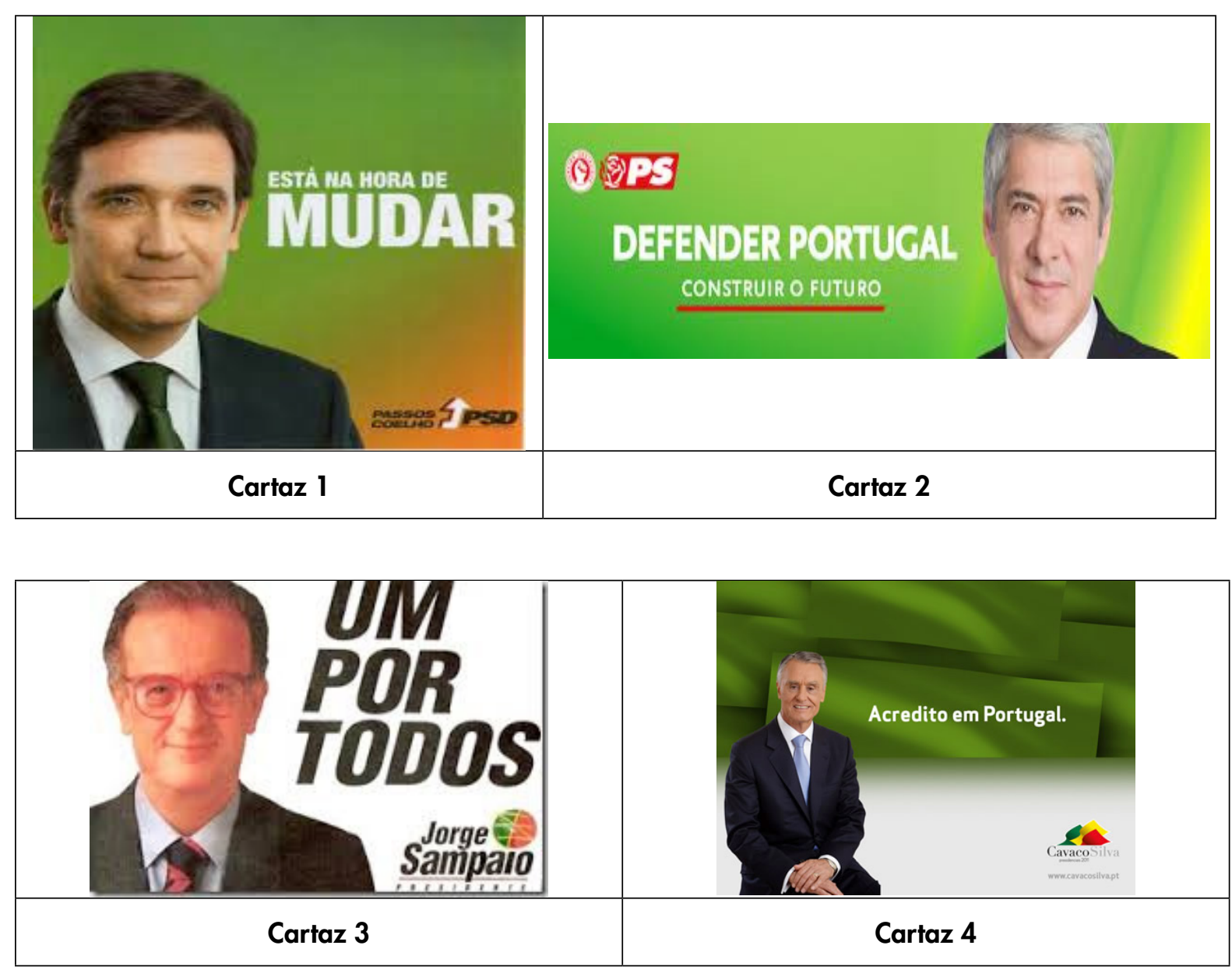

A nossa proposta é que os debates politicos eleitorais, e a importância que adquirem em campanha, participam neste processo geral de personalização, que se observa no cenário político português, ao serviço de uma mudança mais global de presidencialização das eleições legislativas. E, por essa razão, consideramos que a construção discursiva dos debates dará conta desta deriva das campanhas eleitorais.

Alguns factos, e análises académicas, confirmam esta proposta: em 1983 ocorreu pela primeira vez um debate entre os quatro líderes dos maiores partidos ${ }^{5}$. Os

5 CDS, PSD, PS e PCP. 
Linha D'Água (Online), São Paulo, v. 30, n. 1, p. 9-33, jun. 2017

investigadores são unânimes em datar desta campanha o início da personalização das eleições legislativas 6 .

$\mathrm{Na}$ atualidade, mantém-se a tradição dos debates eleitorais. A imagem do líder tem cada vez mais importância, a personalização/presidencialização das eleições legislativas acentuou-se ${ }^{7}$, mercê, nomeadamente, da mediatização da política. Para investigadores da área da Ciência Política, como Lobo (2005), a bipartidarização PS-PSD, que caracteriza a cena política portuguesa, dá estabilidade governamental e favorece um processo eleitoral centrado no candidato ${ }^{8}$ :

...the concentration of electoral support around the two major parties guaranteed governmental stability, a stronger premier, and more candidate-centred electoral processes, fuelled by the private media's pressure to presidentialize electoral contests. (LOBO, 2005, p. 284)

O processo de personalização/presidencialização das legislativas parece ter-se já naturalizado no quadro político e social. Os políticos vêm assumindo que são candidatos à função de primeiro-ministro, como se exemplifica nos dois excertos seguintes, relativos a debates eleitorais durante a campanha para as eleições legislativas de 2002 e 2011 :

- O primeiro debate da democracia, que ficou para a História, ocorreu entre os líderes do PS e do PCP, Mário Soares e Álvaro Cunhal, respetivamente, ainda em 1976. Foi um debate que durou quatro horas.

A tradição de debates nas legislativas veio a ser interrompida, durante os governos de Cavaco Silva e retomada em 1995, por Nogueira e Guterres.

7 Esta personalização teve um caráter singular na campanha eleitoral de 2002, marcada por boatos sobre um dos líderes partidários (MARQUES, 2010). No debate então realizado entre os dois líderes dos dois maiores partidos a questão foi colocada como primeiro tema de discussão: "A pré-campanha, no entanto, resvalou para temas e resvalou para insinuações e para boatos sobre a vida privada dos candidatos, com cartazes e frases dúbias. A pergunta é porquê, Eng. José Sócrates?".

8 O atual governo, de responsabilidade do PS é apoiado, pela primeira vez na história da democracia portuguesa, por dois partidos de esquerda, o Partido Comunista Português e o Bloco de Esquerda, situado na esquerda radical. Será uma questão a considerar na análise das futuras eleições. 
Linha D'Água (Online), São Paulo, v. 30, n. 1, p. 9-33, jun. 2017

(1) SL: [...] Acho que deve contar a vida privada, para responder à sua pergunta, só nisto: para demonstrar a coerência entre as propostas que se fazem, para a vida dos outros, nos candidatos a primeiros-ministros e aquilo que nós fazemos na nossa vida.

Debate, campanha eleitoral de 2002, entre Santana Lopes (PSD) e José Sócrates (PS)

(2) PPC: [...] o senhor que é primeiro-ministro nesta altura e que vai a votos COMO primeiro-ministro eu vou como candiDATO a primeiro-ministro o senhor vai a votos $C O M O$ primeiro-ministro (...)

Debate, campanha eleitoral de 2011, entre Pedro Passos Coelho (PSD) e José Sócrates (PS) ${ }^{9}$

Da progressiva personalização das campanhas decorre a saliência da imagem dos políticos, líderes dos diferentes partidos e, por isso, a imagem do adversário constitui um alvo preferencial nestes debates ${ }^{10}$, a descredibilização do líder partidário é um recurso estratégico, plasmado em ataques ad hominem:

(3) JS: [...] isto é Passos Coelho administrador reconhecia não só que a crise internacional tinha atingido o nosso país como Portugal em 2009 se tinha portado bem do ponto de vista económico agora Passos Coelho versão líder de um partido acha que a responsabilidade é toda do governo e que não existe nenhuma responsabilidade da crise internacional.

Debate, 2011.

Também a comunicação social dá por adquirida a condição de candidato a primeiro-ministro, e as eleições são personalizadas no líder, não no partido. No debate em análise, esta característica torna-se saliente, pelo facto de o processo de questionamento instituído pelo moderador no início do debate estabelecer um quadro de discussão personalizado. São imagens pessoais que estão em causa ${ }^{11}$ :

\footnotetext{
9 A partir de agora "Debate, 2011". Os itálicos e negritos, nos excertos analisados, marcam os segmentos alvo da análise.

10 Não só a imagem do adversário é convocada. $\bigcirc$ uso dos pronomes pessoais de primeira pessoa são um indicador nuclear desta personalização.

11 Esta naturalização do processo de presidencialização é facilitada por outras dimensões da
} 
Linha D'Água (Online), São Paulo, v. 30, n. 1, p. 9-33, jun. 2017

(4) VG: José Sócrates, [...]. Neste cenário porque é que os portugueses lhe hão de dar uma nova oportunidade?

Debate, 2011.

(5) VG: Pedro Passos Coelho [...] porque é que os portugueses hão de confiar em si o governo do país num momento tão difícil quando o senhor não tem qualquer experiência governativa não foi secretário de estado não foi ministro não foi presidente de câmara?

Debate, 2011.

E, por isso, tal como foi apontado para os políticos-adversários, também o jornalista-moderador presidencializa as eleições legislativas, assumindo que está perante dois candidatos a primeiro-ministro:

(6) VG: José Sócrates] eu gostava de lhe colocar a seguinte questão [...] o número de desempregados chegou aos seiscentos e noventa mil e pode aumentar nos próximos dois anos que alternativas e que esperanças é que o senhor pode dar a estas pessoas se for reeleito primeiro-ministro?

Debate, 2011.

\subsection{Debates eleitorais e televisão}

A personalização das eleições beneficia, pois, da interligação da esfera da política com a esfera da comunicação social, e, em particular, a televisão. A visibilidade da televisão, a que os políticos não se esquivam, bem pelo contrário, tem um papel fundamental; é da mediatização da política que dá conta a afirmação de Mário Soares, ex-líder do PS, ex-primeiro-ministro e ex-presidente da república, no programa $\mathrm{O}$ Século do Povo, difundido em 26 novembro 1997: "Os políticos que não passam bem na televisão dificilmente se poderão impor nas democracias modernas.” ${ }^{12}$. O

vida política portuguesa, nomeadamente, a revisão constitucional de 1982 que reduziu os poderes presidenciais; também a bipolarização partidária, como já apontado, reforça a liderança.

12 Aí a personalização é muitas vezes acompanhada de uma vedetização dos políticos, i.e., "la mise en spectacle de leur personalité" (COSSART, P.; TAÏEUB, E., 2011 ). 
Linha D'Água (Online), São Paulo, v. 30, n. 1, p. 9-33, jun. 2017

peso "político" da televisão é ainda mais evidente em tempos de campanha eleitoral. É um dado adquirido que, como refere Salgado (2007, p. 9), “...é através dos meios de comunicação social e, principalmente, pela televisão, que os eleitores tomam contacto com a campanha eleitoral e com as propostas dos partidos...”.

No que concerne ao género debate político eleitoral, este é quase privativo da televisão ${ }^{13}$. De facto não tem havido outro lugar institucional para a construção deste tipo de interação que, no entanto, tem lugar central nas grelhas de programação televisivas. O debate é um momento alto da campanha eleitoral.

A Entidade Reguladora da Comunicação Social secunda esta perspetiva e acentua a centralidade dos debates eleitorais, ainda que reservando para os meios de comunicação uma exterioridade que na verdade não possuem:

A democracia representativa requer competição entre os atores que se propõem ao desempenho de funções eletivas. No período eleitoral, torna-se particularmente importante o papel dos meios de comunicação social enquanto mediadores $e$ veículos de informação, dado que na maior parte das vezes, é através deles que os cidadãos conhecem as propostas dos candidatos e formam as suas convicções. Os debates eleitorais, difundidos pela televisão (...) são momentos privilegiados para dar a conhecer, não apenas as propostas eleitorais das diferentes candidaturas, como os próprios candidatos, colocados numa posição de combate político por excelência. Deliberação 118/2013 (OUT), Conselho Regulador da ERC, 23 de abril de 2013

É necessário ter em conta que o debate eleitoral faz parte da agenda política, mas também da agenda mediática. É um evento central para a construção das relações necessariamente complexas entre estas duas esferas de atividade linguística, a política e a mediática. Face aos debates televisivos, outros modos de atividade política eleitoral bem como a sua divulgação, mostram ser mais limitados, como é o caso da campanha eleitoral de rua (as arruadas) com um impacto "localizado" ainda que divulgada nos telejornais, que não dão, no entanto, muito espaço para a reportagem alargada. Sobressaem, pois, os debates como a possibilidade forte de divulgar uma proposta política, mas, sobretudo, como a possibilidade de confronto

13 Só as eleições autárquicas "usam" as rádios locais para debates. As rádios nacionais difundem os debates realizados na televisão. 
Linha D'Água (Online), São Paulo, v. 30, n. 1, p. 9-33, jun. 2017

político e consequente espetacularização da política (CHARAUDEAU, 2011, MARQUES, 2013b).

Contudo, este não é o objetivo único nem último, antes é um meio para uma outra finalidade de persuasão, pois «vencer» o debate, não é vencer o oponente, o objetivo é, antes, ganhar eleitores (CHARAUDEAU, 2010).

Colocámos como hipótese que é nesta ligação aos eleitores que a relação interpessoal entre os dois adversários se molda e justifica a ocorrência estratégica da atenuação.

\section{Quadro teórico e metodológico \\ 2.1 Os debates políticos eleitorais}

Enquanto subgénero do discurso político, o debate, e em particular o debate político eleitoral, é um género agonal, de radicalização do dissenso, de confronto direto entre os participantes, que pretendem obter a adesão dos eleitores não apenas pelas propostas programáticas que apresentam mas também, talvez sobretudo, pela descredibilização do adversário político e credibilização própria, o que os aproxima de um registo populista (CHARAUDEAU, 2011, MARQUES, 2013b). O confronto verbal não é, obviamente, absoluto, na medida em que os interlocutores têm que preservar as regras básicas da comunicação, que, no caso do confronto político, estabelecem restrições fortes, se o participante no debate pretende ganhar as eleições.

Coloca-se, assim, a questão da construção, negociação e gestão da relação interpessoal. O debate dá origem a um conjunto de outros eventos discursivos, de comentário, na televisão e nos jornais nomeadamente, que criam/mostram a reação da opinião pública ao debate realizado. E a vertente pessoal é efetivamente valorizada nesta apreciação pública, como ilustra este excerto do jornal Público, de 7 de setembro de 1995, a propósito do debate entre António Guterres, líder do PS, e Fernando Nogueira, líder do PSD, avaliado em termos da imagem dos interlocutores: "Foi um debate ganho no primeiro minuto: a impressionante descontração de António Guterres chocou de imediato com a mal disfarçada insegurança de Fernando Nogueira". 
Linha D'Água (Online), São Paulo, v. 30, n. 1, p. 9-33, jun. 2017

Pretendemos, assim, desenvolver a nossa hipótese de trabalho acima enunciada, isto é, que a atenuação linguística, realizada, em cada momento da interação, segundo procedimentos linguístico-discursivos diversos, constitui uma estratégia nuclear neste processo de construção de uma relação interpessoal dominada pelo confronto, que o efeito de personalização agudiza. O caráter público da interação sublinha a importância da imagem que cada um constrói de si, na necessária relação com o outro, o adversário, mas também com os eleitores. A atenuação, como estratégia, faz parte da orientação argumentativa do debate.

\subsubsection{Parâmetros caracterizadores do debate político eleitoral televisivo}

Salientamos alguns dos parâmetros de género que sustentam a nossa análise. $\mathrm{O}$ debate político eleitoral televisivo é uma interação discursiva planeada, aliás, cuidadosamente planeada ${ }^{14}$; daí a necessidade de relacionar os mecanismos da atenuação com este caráter planeado da interação, que obviamente não é absoluto. Deve, no entanto, notar-se que o planeamento determina as linhas fundamentais temáticas e argumentativas de que a relação interpessoal participa.

Quanto ao número de participantes, o debate é um plurílogo, que agrega por um lado, o jornalista-moderador e os políticos-oponentes/participantes-adversários no debate, presentes no mesmo espaço físico da televisão, e, num outro plano, mas igualmente fundamental e atuante, o público, na função preferencial de eleitorado.

O jornalista é um moderador, com diferentes responsabilidades na gestão da interação, cabendo-lhe fazer perguntas, introduzir os tópicos que irão ser objeto de discussão, gerir o tempo e o uso da palavra e, ainda, enquadrar a interação discursiva no programa televisivo em curso, estabelecendo a ligação explícita com os telespectadores, os portugueses, de quem aliás se apresenta como porta-voz:

(7) VG: há outras questões que os portugueses querem saber

14 Os avanços tecnológicos tornam cada vez mais presente a equipa de assessores, não apenas antes do debate, mas também durante o debate (ver RIBEIRO, 2015). 
Linha D'Água (Online), São Paulo, v. 30, n. 1, p. 9-33, jun. 2017

É este estatuto que, a nosso ver, justifica discursivamente a agressividade do tipo de perguntas que realiza, o modo como interage com os outros participantes ${ }^{15}$. No entanto, não é apenas o papel de porta-voz, que o jornalista assume; mostra-se como locutor individual, em (10), no uso do deítico Eu e do verbo volitivo: "VG: Pedro Passos Coelho [...] eu gostava de analisar [...]". O seu posicionamento face aos políticos é, pois, complexo.

Passando agora aos políticos, estes participam na gestão da interação para além do papel que lhes é atribuído de agentes do confronto, i.e., oponentes ou adversários; nomeadamente, tentam, e conseguem com frequência, influenciar o rumo do debate, a nível temático, mas também ao nível da transição de turno, de tomada e manutenção da vez, ou seja, interferindo nas funções discursivas atribuídas ao jornalista-moderador. As estratégias são variadas, com destaque para as sobreposições, mas também, as repetições e os evitamentos totais ou parciais, entre outros processos usados. O excerto abaixo constitui um dos exemplos desta situação de mudança de turno, com evitamento total do tema proposto pelo jornalista-moderador:

(8) PPC: [...] disse a ministra da saúde vamos adotar também o modelo c das unidades eh de saúde familiares e vamos abri-las às policlínicas e às cooperativas de médicos

VG: [é isto que o senhor chama de fim do serviço nacional de saúde, José Sócrates? $(())]$

JS: senhor doutor Passos Coelho o senhor doutor tem em vários momentos da sua intervenção politica posto em causa a minha palavra e acabou de a pôr em causa há [...]

Debate, 2011.

O estatuto discursivo dos três interlocutores e a relação interpessoal que constroem na interação são diversos, por causa dos papéis discursivos e sociais que assumem. As formas de tratamento (FT) dão conta desta diferença de estatuto. Jornalista e políticos estabelecem entre si relações de distanciamento ${ }^{16}$.

15 Ver MARQUES (2013a) sobre a agressividade jornalística na entrevista televisiva.

16 Apenas uma vez o jornalista é tomado como alocutário a partir do uso de uma FT 
Linha D'Água (Online), São Paulo, v. 30, n. 1, p. 9-33, jun. 2017

O jornalista usa como formas de tratamento, formas nominais constituídas pelo nome completo (o nome por que são conhecidos dos portugueses), assumindo uma relação distante e formal ${ }^{17}$ :

(9) VG: José Sócrates, Portugal está de novo em recessão o desemprego atingiu um valor record e eeh o país foi obrigado a pedir um resgate financeiro internacional.

Debate, 2011.

(10) VG: Pedro Passos Coelho ((incompreensível)) eu gostava de analisar [...]

Debate, 2011.

Os políticos-oponentes usam, entre si, formas diversas de tratamento, em alocução e delocução, para construir uma relação interpessoal formal e reciprocamente deferente, de acordo com os papéis interpessoais simétricos dos dois contendores:

(11) PPC: [...] um comentário sobre o que disse o engenheiro Sócrates [...]

(12) JS: [...] o doutor Passos Coelho considerou esse projeto da revisão constitucional $[\ldots]$

(13) PPC: [...] senhor engenheiro José Sócrates se hoje o estado social está maltratado e o sinal mais evidente da falência do modelo que o senhor seguiu está [...]

nominal: "JS: [...] tem escrito no seu livro e repare bem Vítor Gonçalves o texto constitucional deve ser alterado em conformidade com a introdução de copagamentos no setor público da saúde [...]", mas que curiosamente lhe atribui a função de testemunha; o alocutário principal é sempre o adversário.

17 As formas de tratamento usadas pelos jornalistas em interações televisivas com políticos têm sofrido evoluções que não estão ainda analisadas. Veja-se, por exemplo, as FT usadas no debate eleitoral das legislativas de 2002:" RGC: Tem que terminar, Dr. Santana Lopes. Eu, antes de perguntar ao Eng. José Sócrates se quer replicar...". 
Linha D'Água (Online), São Paulo, v. 30, n. 1, p. 9-33, jun. 2017

(14) JS: [...] mas nem sempre o senhor doutor pensou assim porque $o$ senhor doutor quando era administrador $[\ldots]$

Debate, 2011.

Outras formas de tratamento podem ocorrer, mas servem outros objetivos, nomeadamente o de expor uma imagem negativa do adversário pelo confronto com o tópico em discussão. No exemplo seguinte, a forma de tratamento "sr. Primeiro-Ministro" faz sobressair o contexto temático em que ocorre; tratando-se de uma questão da responsabilidade governamental, o primeiro-ministro não a deveria ignorar como pretende o locutor, pelos usos da estrutura interrogativa "sabe sr. Primeiro-ministro" ${ }^{18}$. Acresce o facto de o adversário estar ali na qualidade de líder do PS, não na de Primeiro-ministro. É a responsabilização acrescida que o locutor pretende:

(15) PPC: [...] porque os copagamentos existem na sociedade portuguesa [sabe senhor Primeiro-ministro

JS: (( ))]

PPC: sabe senhor Primeiro-ministro trinta por cento da despesa disse-o há pouco é feita por privados mesmo na área da medicina convencionada

Debate, 2011.

\subsection{Atenuação: abordagem teórico-metodológica}

A proposta teórica de Briz, de que destaco Briz (2013) e Briz \& Alberda (2013), sobre a atenuação linguística, suas características e funções está na base da análise que irei desenvolver. Segundo este autor,

A atenuação linguística relaciona-se sempre com a eficácia e com a atividade argumentativa (...) é uma atividade argumentativa (retórica) e estratégica de minimização da força ilocutória e do papel dos participantes na enunciação, para conseguir chegar-se com sucesso à meta prevista e que é usada em contextos

18 Este é um funcionamento comum a outras línguas como o espanhol. Veja-se MAPELLI (2010, 566): "Por ejemplo, con la pregunta retórica introducida por ¿̇sabe? se insiste en el desinterés por un tema y en la desinformación acerca de un problema." 
Linha D'Água (Online), São Paulo, v. 30, n. 1, p. 9-33, jun. 2017

situacionais, com menor carácter imediato ou que requerem ou se deseja menos imediatez comunicativa. (BRIZ, 2013, p. 283 e 284)

A proposta de Briz distancia-se de outras abordagens da atenuação, nomeadamente na relação estabelecida com a eficácia e atividade argumentativa e, complementarmente, a distinção que estabelece entre atenuação e cortesia:

Os trabalhos e referências dedicados ao tema por parte dos analistas da cortesia são cada vez mais numerosos, embora, neste caso, parece que a atenuação e a cortesia são consideradas um mesmo conceito. (BRIZ, 2013, p. 283)

Briz faz referência a uma questão teórica, já antes discutida e especificada no âmbito do grupo Val.Es.Co, como é o caso de Marta Albelda (2005) para quem "las actividades de cortesía no se realizan solo mediante estrategias de atenuación y que existen otras estrategias que tienen que ver con la cortesía y que no son atenuantes.”. Subentende-se também que há estratégias que têm a ver com a atenuação e não são corteses.

Reconhecendo que o conflito é desencadeador da estratégia de atenuação e que este é o mesmo princípio da cortesia, A. Briz afirma a interseção entre atenuação e cortesia, mas não a sua sobreposição e consequente indistinção. A cortesia constitui um princípio explicativo da atenuação, mas não é o único. Uma abordagem mais adequada da atenuação linguística, que tem implicações na construção da imagem que o locutor constrói de si no discurso, deverá antes dar relevo a questões de eficácia argumentativa. É a este nível que deve ser situada a atenuação no processo de construção do debate político eleitoral.

A atenuação é uma categoria pragmática, constitui uma estratégia discursiva, de aproximação, que visa "obter a adesão do outro e cuidar da relação interpessoal", e simultaneamente de distanciamento do conteúdo do dizer, a fim de "mitigar a força ilocutória"; como atividade discursiva ocorre com três funções, de autoproteção, de prevenção, e reparação de situações de conflito que implicam ataques à imagem própria ou à imagem do adversário. Enquanto categoria pragmática, a atenuação é sensível ao contexto. Daí a necessidade de uma metodologia que permita identificar os contextos em que ocorre: "É necessário tentar obter uma identificação 
Linha D'Água (Online), São Paulo, v. 30, n. 1, p. 9-33, jun. 2017

confiável de quando um mecanismo funciona como atenuador." (BRIZ, 2013, p. 297). O investigador identifica três partes em toda a situação de atenuação " o segmento desencadeador, o que favorece ou provoca a atenuação; o elemento ou segmento atenuador, o que atenua, e o segmento atenuado, o que se atenua.", que constituem o contexto interacional concreto e formam os critérios de reconhecimento da atenuação, ou da função atenuadora de um elemento verbal ou não verbal.

\section{Lugares de atenuação no debate político eleitoral e construção das imagens}

As características do debate político eleitoral, marcado pela agressividade, não apenas dos oponentes, mas também do questionamento levado a cabo pelo jornalista-moderador, acentuam a necessidade de ter em atenção os contextos que favorecem a ocorrência de atenuação. $O$ facto de o debate eleitoral se caracterizar por uma relação agónica, de confronto, com recurso sistemático a estratégias de desvalorização do adversário, é fundamental para determinar se ocorre atenuação, onde ocorre, que funções discursivas serve e que mecanismos linguísticos usa.

Restringimos a análise da atenuação neste debate político eleitoral a duas vertentes básicas, a partir da estrutura da interação ${ }^{19}$ : a) as situações de uso da vez, a intervenção monologal; b) os lugares de transição de turno, porque tomar e ceder a vez constituem momentos da interação particularmente instáveis, pela disputa a que com frequência dão origem. Neste caso, há ainda a considerar dois tipos de trocas, de acordo com os participantes: trocas entre o jornalista-moderador e o político-adversário e entre os dois adversários.

\subsection{Contexto interativo e relação jornalista-político no par adjacente pergunta-resposta}

A relação interacional entre os participantes no debate, jornalista e políticos, ocorre em estruturas marcadas pelo par adjacente pergunta-resposta, que determina também a transição de turno. Quer as perguntas, pelo seu conteúdo e/ou forma

19 Sobre a estrutura da interação verbal dialogal, ver Kerbrat-Orecchioni, 1990. 
Linha D'Água (Online), São Paulo, v. 30, n. 1, p. 9-33, jun. 2017

quer a imposição da cedência da vez são fatores de particular tensão. Sobressai na abertura do debate (exemplos (5) e (6) agora retomados como (16) e (17)) um questionamento agressivo, porque personalizado, configurando um ataque $a d$ hominem, que põe em causa, para os dois interlocutores, a capacidade para ocupar o lugar de Primeiro-ministro:

(16) VG: José Sócrates, Portugal está de novo em recessão o desemprego atingiu um valor record e eeh o país foi obrigado a pedir um resgate financeiro internacional. Neste cenário porque é que os portugueses lhe hão de dar uma nova oportunidade?

Debate, 2011.

Para o segundo interlocutor, o jornalista usa a mesma estratégia de confronto, mas a personalização do debate é ainda mais explícita:

(17) VG: Pedro Passos Coelho antes de dar tempo para responder a estas afirmações de José Sócrates eu perguntava-lhe porque é que os portugueses hão de confiar em si o governo do país num momento tão difícil quando o senhor não tem qualquer experiência governativa não foi secretário de estado não foi ministro não foi presidente de câmara?

Debate, 2011.

Ambas as perguntas desencadeiam réplicas que recorrem a diversos mecanismos de atenuação com função de autoproteção:

(18) JS: ((ruído)) não se trata de dar uma nova oportunidade trata-se de fazer uma escolba.

Debate, 2011.

Em (16), a agressividade da pergunta, que obriga o interlocutor não só a responder, mas a justificar-se, é reforçada pela ativação de um implícito, a partir do adjetivo nova, ameaçador para a face de JS, enquanto pressupõe que este já teve 
Linha D'Água (Online), São Paulo, v. 30, n. 1, p. 9-33, jun. 2017

uma oportunidade e a desperdiçou. Este é o elemento desencadeador do conflito, da ameaça à imagem do interlocutor, que o político recupera na sua intervenção reativa; o segmento atenuado é produzido por JS, através de um processo de reformulação que substitui dar uma nova oportunidade por fazer uma escolha. Constitui uma reorientação argumentativa e, simultaneamente, um reposicionamento face ao alocutário, autoprotegendo-se. A substituição pelo lexema escolha, agregado ao partido (19), reforça este movimento discursivo e argumentativo e mitiga a ameaça inicial. O locutor coloca-se deliberadamente em segundo plano, recuperando a dimensão partidária das eleições legislativas:

(19) [...] eu acho que a escolha entre o ps e o psd reside fundamentalmente aí. E se nós nos eh concentrarmos naquilo que são as duas escolhas entre mim e o doutor Passos Coelho entre os projectos do ps e do psd [...]

Debate, 2011.

A resposta de $\mathrm{PPC}$ à pergunta inicial que lhe foi dirigida pelo moderador, também ela agressiva, como vimos, por esboçar uma imagem de incompetência do interlocutor, é atenuada, desde logo pela saudação inicial de PPC ("muito boa noite"), que mostra uma relação interpessoal cordial, mas visa também, o que não é secundário em termos de orientação argumentativa, uma avaliação positiva da sua imagem, uma imagem de urbanidade, que é reforçada, de seguida, por um longo ato de justificação por analogia com uma situação real, a de Inglaterra, e que atenua a ameaça inicial, produzida pelo locutor-jornalista:

(20) PPC: muito boa noite sabe que (pausa) David Cameron que é atual primeiro ministro de Inglaterra também não fez parte de nenhum governo e no entanto existe uma forte expectativa sobre o desempenho do que ele pode fazer como primeiro-ministro em Inglaterra e é mais novo de resto já agora para acrescentar o tão badalado inconveniente que às vezes me apontam por ter quarenta e seis anos.

Debate, 2011. 
Linha D'Água (Online), São Paulo, v. 30, n. 1, p. 9-33, jun. 2017

A relação entre o jornalista e os participantes no debate é dinâmica, com momentos de maior tensão, mas também de atenuação dessa tensão. Com efeito, nas tomadas de palavra do jornalista-moderador, realizadas ao longo do debate, a agressividade a que os atos de pergunta podem dar origem favorece o recurso a mecanismos de atenuação com função de prevenção. O jornalista-moderador recorre sobretudo a marcas verbais de distanciamento, pelo uso do pretérito imperfeito ou de verbos modais, que atenuam a força ilocutória diretiva do ato realizado:

(21) VG: Pedro Passos Coelho ((incompreensível)) eu gostava de analisar cada um desses elementos $(())$ só para completar gostava de [...]

Debate, 2011.

(22) VG: Pedro Passos Coelho antes de dar tempo para responder a estas afirmações de José Sócrates eu perguntava-lhe porque é que [...]

Debate, 2011.

(23) VG: Jósé Sócrates quer responder a esta questão?

Debate 2011.

\subsection{Transição de vez e expressões ritualizadas de atenuação}

No debate, com incidência nos momentos de transição de turno, com cedência ou tomada de turno entre os oponentes, abundam expressões ritualizadas de atenuação. São fórmulas desvalorizadas desde Labov e Fanshel (1977) como "frozen mitigators". Maria Marquez (2012, p. 195) afirma que estas fórmulas, como "por favor", não são atenuadores, porque "Para ciertos usos, y en función del contexto, la repetición de esta fórmula asociada a una situación verbalmente agresiva puede haber provocado que se vacíe de su contenido atenuador original y se convierta en una señal de amenaza." ${ }^{20}$ De facto, as características globais do género discursivo debate

20 Brown e Levinson (1987), parecem discordar quando afirmam: "One diagnostic of ritual is often held to be repetitive or pre-patterned behaviour. (...) polite formulae clearly form an important focal element (...) in the distinction between "personal tact" and "positional" politeness." 
Linha D'Água (Online), São Paulo, v. 30, n. 1, p. 9-33, jun. 2017

eleitoral, que visa o dissenso, a desacreditação do adversário e o reforço da sua própria credibilidade, suportam esta análise ${ }^{21}$. No entanto, sendo clara e justificada tal avaliação, essas expressões ritualizadas não são inúteis nem irrelevantes, antes constituem um recurso importante para a consecução das finalidades globais do debate eleitoral, e em particular para a dimensão de personalização que se joga na campanha eleitoral. Como referimos, o discurso político, e o discurso eleitoral em especial, pretende ser eficaz, obter resultados positivos nas eleições. $\mathrm{O}$ voto branco não dá conta da descredibilização do adversário, mas da incapacidade dos agentes políticos para se imporem. Estes modos de construção da relação discursiva, com adversário, mas também com o eleitorado, participam na construção de uma imagem positiva necessária, entre muitas outras dimensões, ao sucesso eleitoral.

As expressões cristalizadas, ainda que enfraquecidas na sua função atenuadora, contribuem para mostrar um comportamento adquirido, de prevenção e mitigação da ofensa à imagem do adversário, que valoriza, na verdade, a imagem do locutor aos olhos dos eleitores. Creio que se aplica aqui a finalidade da atenuação, enunciada por Briz, segundo o qual esta é uma estratégia discursiva usada para ganhar o jogo conversacional, mas a que acrescentamos a necessidade de ganhar o jogo eleitoral.

Dadas as finalidades do debate eleitoral e o contexto sociopolítico de personalização das eleições legislativas, os recursos linguísticos de atenuação são, em primeiro lugar, um mecanismo ao serviço da argumentação, que pela sua sistematicidade se torna uma marca de estilo do género debate eleitoral.

O exemplo seguinte dá conta destas trocas marcadas pela tensão interacional, reforçada pela agressividade do tom usado que mostra, a par de outros recursos linguísticos, a presença de emoções negativas como a irritação. Contudo, está em causa uma agressividade que é, ainda assim, contida e mitigada pela ocorrência das expressões atenuadoras ritualizadas; os oponentes estão empenhados na construção de um ethos de credibilidade que impõe as suas regras ${ }^{22}$ :

21 Veja-se o seguinte exemplo: "PPC: §não me interrompa se fizer favor [tom irritado]".

22 Há uma imagem ou ethos coletivo, de classe, que determina a construção do ethos discursivo. Aos políticos, atribui-se uma imagem de fairplay que deve ser respeitada, sob pena de se ver descredibilizado. Em Portugal, Alberto João Jardim (PSD) ou Marinho Pinto (PT) são exemplo desse desregramento verbal descridibilizador.

A questão da "saine colère" no debate Sarkozy - Royal, em 2007, em França, não é mais 
Linha D'Água (Online), São Paulo, v. 30, n. 1, p. 9-33, jun. 2017

(24) PPC: existe [mas deixe-me dizer

JS: estou a falar-lhe no serviço nacional de saúde

PPC: deixa-me dizer mas deixe-me dizer

JS: como o senhor disse que eu estava a mentir

PPC: não está no programa

JS: faz favor de dizer

PPC: não está no programa eleitoral

JS: ((incompreensível))] ou não defende o copagamento

PPC: o senhor deixa-me responder responder se fizer favor?

JS: mas o senhor disse

PPC: o senhor não me interrompa porque assim as pessoas que estão em casa não vão perceber vamos mudar de técnica

Debate, 2011.

A última réplica deste excerto diverge das anteriores no recurso linguístico de atenuação usado. O locutor opta por uma estrutura não formulaica. $\mathrm{O}$ ato de justificação do ato diretivo, agressivo na forma direta escolhida (o senhor não me interrompa), permite ao locutor distanciar-se, autoproteger-se, ao atribuir a premência da ordem a uma entidade mais forte, identificada com os portugueses que participam no debate como espectadores. Mas é na interpretação desta situação como momento de tensão, em que ocorrem marcas de atenuação, que esta tática do locutor ganha importância. De facto, a opção por um atenuador não cristalizado pode reforçar, em meu entender, a dimensão de atenuação que as estruturas cristalizadas ainda possuem e que o locutor usa para manter a vez. A última réplica faz parte de um comportamento local coerente (mas também global) de gestão das faces.

Situação diversa é, talvez, a que decorre da negociação da cedência de vez com o jornalista-moderador. $\mathrm{O}$ confronto, podendo existir, não constitui um objetivo discursivo. Os segmentos abaixo sublinhados pretendem reparar, pela repetição do ato de pedido, este ataque ao território do interlocutor, reparar o atropelo à posição discursiva do moderador, porque, como sabemos, o uso da palavra é exercício

do que a discussão sobre o ethos de Presidente da República. 
Linha D'Água (Online), São Paulo, v. 30, n. 1, p. 9-33, jun. 2017

de poder e neste caso particular pode decidir o resultado do debate, enquanto o silêncio seria admissão de derrota:

(25) VG: José Sócrates

PPC: aquilo que eu defendi

VG: $[(())$

PPC: mas deixe-me só concluir

JS: (( ))]

PPC: com certeza (( )) mas deixe-me só concluir

Debate, 2011.

\subsubsection{Gerir a intervenção}

Em termos das intervenções, a atenuação tem como função principal construir mais uma vez uma imagem positiva do locutor. São sempre estratégias de autoproteção, ainda que possam ocorrer como reparação e prevenção. A relação de dissenso que caracteriza o debate eleitoral contextualiza estas ocorrências, mas o processo de personalização que domina as campanhas é também um dado a considerar na saliência que é dada a tais estratégias, não só pela frequência da sua ocorrência mas também pela acumulação de recursos linguísticos de atenuação. No exemplo seguinte, em contexto de clara desvantagem para o locutor confrontado com a acusação de não ter opiniões duráveis e consistentes, há uma acumulação de recursos linguísticos de atenuação que ilustram a importância da estratégia:

(27) $[. .$.$] e eu quando porventura mudo de opinião, porque a realidade muda e nós$ devemos seguir a realidade e não procurar [...] e não procurar pintá-la de outra maneira assumo as minhas diferenças de opinião [...]

O reconhecimento de que mudou de opinião, configurando uma situação negativa para o locutor, é atenuado, em primeiro lugar, pelo advérbio modalizador, com valor epistémico (porventura), mas leva-o ainda a reforçar a autoproteção da sua imagem, mudando o centro deítico de EU para NÓS. É uma estratégia de impessoalização, segundo Briz, que atenua a ameaça, e está, ainda, encaixada num 
Linha D'Água (Online), São Paulo, v. 30, n. 1, p. 9-33, jun. 2017

outro recurso de atenuação, o ato de justificação. Só depois de se ancorar numa opinião genérica como justificação é que o locutor volta a assumir a responsabilidade da enunciação. A ausência de modalizadores em "assumo as minhas diferenças de opinião" faz com que o locutor se mostre como o único responsável da verdade da asserção, que tem um valor de conviç̧ão forte; por um movimento argumentativo a que agrega diversas estratégias de atenuação, o locutor passa de uma situação de desvantagem, com imagem de inconstância, para uma situação de vantagem, com imagem de firmeza moral.

\section{À guisa de conclusão}

Pretendeu-se, aqui, articular a análise dos níveis macro e micro dos discursos a fim de mostrar a vertente de personalização, num quadro alargado de presidencialização da democracia portuguesa, que caracteriza os debates políticos televisivos em campanha eleitoral, e o modo como interfere nas estratégias de atenuação usadas pelos participantes no debate eleitoral, ao serviço da relação interpessoal e da construção das respetivas imagens dos participantes.

Não foi feito um levantamento exaustivo dos recursos linguísticos usados, antes se procurou mostrar como a dinâmica interacional condiciona as estratégias de atenuação, particularmente presentes em lugares de transição de vez marcados por uma grande instabilidade que ameaça as imagens dos participantes.

Abordámos, ainda, a atenuação na relação com o género discursivo, neste caso o debate político eleitoral. A atenuação, enquanto estratégia discursiva presente neste género discursivo não visa, em primeiro lugar, atenuar discrepâncias de opinião, mas sim atenuar o efeito de agressividade entre os oponentes, tendo em conta a relação interpessoal que estabelecem com o eleitorado, e construir assim uma imagem de credibilidade que assegure o êxito nas eleições.

De facto, nas relações interpessoais construídas bem como nos conteúdos representados, os interlocutores-oponentes têm como finalidade desacreditar o adversário e, simultaneamente, velar pela imagem própria como forma de aproximação ao terceiro participante, o eleitorado. São, por isso, fundamentais as estratégias de autoatenuação; e quando a atenuação tem valor de heterorreparação ou heteroprevenção 
Linha D'Água (Online), São Paulo, v. 30, n. 1, p. 9-33, jun. 2017

é ainda uma forma indireta de valorização e autoproteção da imagem. Deste modo, encontramos nestes funcionamentos a superação do paradoxo gerado pela presença da atenuação como estratégia fundamental num género discursivo político, marcado pelo dissenso. Face ao objetivo primeiro de convencer o eleitorado, a proteção da imagem do outro é uma tática ao serviço da eficácia argumentativa.

\section{Referências}

ALBELDA, M. Discordancia entre atenuación/cortesía e intensificación/descortesía en conversaciones coloquiales. In: BLAS, J. L; CASANOVA, M.; VELANDO, M. (eds.). Discurso y Sociedad. Contribuciones al estudio de la lengua en contexto social. Servicio de publicaciones de la Universidad de Castellón, 2005, pp. 581-590 (draft disponível online: http://www.valesco.es/ web/Val.Es.Co/Miembros/Albelda_Discordancia\%20atenuacion_cortesia.pdf) (acesso: 12 de setembro 2014).

BRIZ, A. Español coloquial en la conversación. Esbozo de pragmagramática. Madrid: Ariel Lingüística, 2009.

BRIZ, A. A atenuação e os atenuadores: estratégias e táticas. In: Linha d’Água, n. 26 (2), 2013, p. 281-314.

BRIZ, A.; ALBELDA, M. Una propuesta teórica y metodológica para el análisis de la atenuación lingüística en español y portugués. La base de un proyecto en común (ES.POR.ATENUACIÓN). In: Onomazéin, n. 28, 2013, pp. 288-319.

BROWN, P.; LEVINSON, S. Politeness. Some universals in language use. Cambridge: CUP,1987.

CHARAUDEAU, P. O discurso propagandista: uma tipologia. In: MACHADO, I. L.; MELLO R. (orgs.). Análises do discurso boje, vol. III. Rio de Janeiro: Nova Fronteira, 2010, p. 57-78.

CHARAUDEAU, P. Réflexions pour l'analyse du discours populiste. In: Mots. Les langages du politique, n. 97, 2011, p. 101-116.

COSSART, P.; TAÏEUB, E. Spectacle politique et participation. Paris: Ed Sorbonne, 2011 
Linha D'Água (Online), São Paulo, v. 30, n. 1, p. 9-33, jun. 2017

ESPÍRITO SANTO, P. Comunicação e política nos discursos presidenciais de tomada de posse 1976-2006. In: Revista de Estudos em Comunicação, n. 2, 2007.

FREIRE, A.; PINTO, A. O Poder dos Presidentes. A República Portuguesa em Debate. Lisboa, Campo da Comunicação, 2005.

KERBRAT-ORECCHIONI, C. Analyse du discours-en-interaction. Paris: A. Colin, 2005.

KERBRAT-ORECCHIONI, C. Les interactions verbales, tome 1, Paris: A. Colin, 1990.

LABOV, W.; FANSHEL, D. Therapeutic discourse: psychotherapy as conversation. New York: Academic Press, 1977.

LOBO, M. 2005, The presidentialization of Portuguese democracy?. The Presidentialization of Politics in Democratic Societies: A Framework for Analysis, 269-288.

MARQUES, M. A. Discours Présidentiels au Portugal: un regard pluridisciplinaire. Mots. Les langages du politique, n. 112, 2016, p. 125-132.

MARQUES, M. A. Imagens (entre)vistas. A construção de identidades na entrevista política televisiva. In: SILVA, A.; MARTINS, J.; MAGALHÃES, L.; GONÇALVES, M. (Orgs.). Comunicação Politica e Económica. Dimensões cognitivas e discursivas. Braga: UCP/Publicações da Faculdade de Filosofia, 2013a, p. 271-287.

MARQUES, M. A. Politique, humour et campagne électorale. Les enjeux d'une politique-spectacle. Mots. Les langages du politique, n. 101, 2013b, p. 61-75.

MARQUES, M. A. Circulation et fonction de la médisance en campagne électorale. In: Cédille - revista de estudios franceses. Monografias 1, 2010, p. 65-79.

MÁRQUEZ, M. 2012, La paradoja de la atenuación en el discurso político. Su funcionalidad argumentativa en las interpelaciones de parlamentarias y parlamentarios andaluces. In: Discurso E Sociedad, vol. 6(1), 2012, pp. 187-215.

MAPELLI, G. Políticos cara a cara: actividades de imagen en el debate electoral. In ORLETTI, Franca; MARIOTTINI, L. (eds.) (Des)cortesia en Español. Espacios teóricos e metodológicos para su estúdio, Roma-Estocolmo: Università degli Studi Roma Tre-EDICE, 2010, pp. 557-574. 
Linha D'Água (Online), São Paulo, v. 30, n. 1, p. 9-33, jun. 2017

POGUNTKE, T; WEBB, P. (eds.). The presidentialization of politics. A comparative study of modern democracies. Oxford: Oxford Scholarship, 2005.

RIBEIRO, V. O spin doctoring em Portugal. Perspectivas de governantes, jornalistas e assessores de comunicação que operam na Assembleia da República. Observatorio (OBS*) Journal, vol. 9, n. 2, 2005, p. 225-256.

SALGADO, S. Os veículos da mensagem política. Estudo de uma campanha eleitoral nos media, Lisboa: Livros Horizonte, 2007.

Recebido: 18/06/2017.

Aprovado: 03/08/2017. 